\title{
Observations on viscosity reduction of PHPA polymer support fluids
}

DOI:

10.1061/41106(379)23

Link to publication record in Manchester Research Explorer

\section{Citation for published version (APA):}

Lam, C., Jefferis, S. A., \& Goodhue, K. G. (2010). Observations on viscosity reduction of PHPA polymer support fluids. In Geotechnical Special Publication/Geotech Spec Publ (pp. 184-191). American Society of Civil Engineers. https://doi.org/10.1061/41106(379)23

\section{Published in:}

Geotechnical Special Publication|Geotech Spec Publ

\section{Citing this paper}

Please note that where the full-text provided on Manchester Research Explorer is the Author Accepted Manuscript or Proof version this may differ from the final Published version. If citing, it is advised that you check and use the publisher's definitive version.

\section{General rights}

Copyright and moral rights for the publications made accessible in the Research Explorer are retained by the authors and/or other copyright owners and it is a condition of accessing publications that users recognise and abide by the legal requirements associated with these rights.

\section{Takedown policy}

If you believe that this document breaches copyright please refer to the University of Manchester's Takedown Procedures [http://man.ac.uk/04Y6Bo] or contact uml.scholarlycommunications@manchester.ac.uk providing relevant details, so we can investigate your claim.

\section{OPEN ACCESS}




\title{
Observations on Viscosity Reduction of PHPA Polymer Support Fluids
}

\author{
Carlos Lam ${ }^{1}$, M. ASCE, Stephan A. Jefferis ${ }^{2}$, and K. Gifford Goodhue, Jr. ${ }^{3}$ \\ ${ }^{1}$ Research Student, Department of Engineering Science, University of Oxford, Parks Road, Oxford, \\ OX1 3PJ, U.K.; carlos.lam@eng.ox.ac.uk \\ ${ }^{2}$ Visitng Professor, Department of Engineering Science, University of Oxford, Parks Road, Oxford, \\ OX1 3PJ, U.K.; stephan.jefferis@eng.ox.ac.uk \\ ${ }^{3}$ Research \& Development Director, KB International LLC, 735 Broad Street, Suite 209, Chattanooga, \\ TN 37409, U.S.A.; gif@kbtech.com
}

\begin{abstract}
Polymer fluids have been used in foundation drilling for many years and yet no previous studies have been reported which assess their sensitivity to shear such as is induced by pumping equipment. A field study has been carried out on two specific polymer products under actual site conditions. It is found that there is a significant loss of viscosity when partially hydrolyzed polyacrylamide (PHPA) fluids are circulated through a centrifugal pump in a loop system. This behavior is quite distinct from that of bentonite slurries which require high shear mixing and recirculation to ensure good hydration. At first sight the sensitivity of PHPA fluids to shear may be perceived as a disadvantage but in fact if shear can be reduced so can on-site energy consumption. A reduction in fluid viscosity was also observed over a standing period between mixing and use, suggesting that a second mechanism may be contributing to the properties change. From the trial results, recommendations are given on pump selection and on the maintenance of fluid properties.
\end{abstract}

\section{INTRODUCTION}

Polymer fluids have been widely used in foundation drilling for nearly two decades in many parts of the world (Corbet et al. 1991; Ho and Tan 1996; Brown et al. 2002; Bustamante and Boato 2005). In contrast to bentonite slurries which are basically dilute clay suspensions (typically $2.5 \%$ to $6 \%$ bentonite in water), polymer fluids develop their viscosity through the hydrodynamic interaction of polymer molecules dissolved in the make-up water. The molecules have high molecular weights, typically between 14 and 17 million and a surface charge density of 30 to $45 \%$ (O'Neill and Reese 1999). It is the interaction between these charged long-chain molecules that gives rise to the solution viscosity and the other polymer properties. The most basic of these polymer fluids are partially hydrolyzed polyacrylamides (PHPAs), which are the subject of this paper. It is appropriate to note that PHPAs are 
by far the most popular type of polymer in the foundation industry, accounting for more than $90 \%$ of all the polymers used today.

Before considering the technical aspects of this paper, it is necessary to expand on the term 'polymer' as applied to excavation support fluids. This is essential for the proper interpretation of this paper and to the successful use of such fluids in practice. Basically, the world of polymers is vast and highly varied and it is fundamental to recognize this when considering these materials. Engineers should not treat polymers as if they were a single product and must recognize their many differences in chemical composition, physical form and properties. To treat all polymers fluids as a single product would be analogous to treating all clay slurries, such as bentonite, attapulgite, kaolin, and native clay as if they were all identical. In this paper, two polymers of very specific chemical composition are considered; both are PHPAs and yet even within this composition we find variations in their properties as will be shown later.

Although bentonite slurries and polymer fluids are two distinctly different systems, when pumped into an excavation, trench or shaft etc., they both work by exerting hydrostatic fluid pressure against the walls of the excavation to prevent groundwater infiltration and to provide a stabilizing force to the excavation. It is well known that bentonite slurries maintain this fluid pressure by forming a filter cake on the exposed soil surface so that fluid loss into the adjacent ground is reduced to low levels (Fleming and Sliwinski 1977). However, pure PHPA fluids cannot form a filter cake although they may do so if there are fine soil/clay particles suspended in the fluid. Fundamentally for fluid loss prevention, it is the rheological properties of PHPA fluids which control their flow into and through the soil pores within the surrounding formation. The rate at which the fluids are lost into the surrounding ground mainly depends their solution viscosity and the resulting viscous drag resistance achieved as the fluid migrates into the soil. Herein lies the major deficiency of PHPAs as excavation-support fluids and the underlying cause for the majority of the stabilization failures seen to date. Without proper monitoring and maintenance of the viscosity, PHPAs will fail in their role as support fluids.

Despite the importance of the viscosity of polymer fluids, little information can be found in the civil engineering literature about its sensitivity to external influences. Majano et al. (1994) report the effects of some chemical contaminants (sodium chloride, gasoline and high $\mathrm{pH}$ conditions) on the viscosity and the side friction of laboratory-scale model piles. In terms of physical interference such as pumping, O'Neill and Reese (1999) argue that diaphragm pumps will cause less damage to the fluids than centrifugal pumps, but they do not present any data to support this thesis. A survey of product literature produced by leading polymer suppliers reveals contradictory advice: one supplier strongly discourages the use of centrifugal pumps whilst others either allow their use or provide no guidance on the matter. To help resolve the issue, a field study was undertaken on a construction site in Glasgow, U.K. where drilled shafts (bored piles) were being installed under the support of PHPA fluids. During the work, opportunity was taken to study the loss of viscosity of 
clean unused PHPA fluids when subjected to the mechanical action of a centrifugal pump. Details of the test conditions are given below.

\section{PLANT SETUP AND TEST EQUIPMENT}

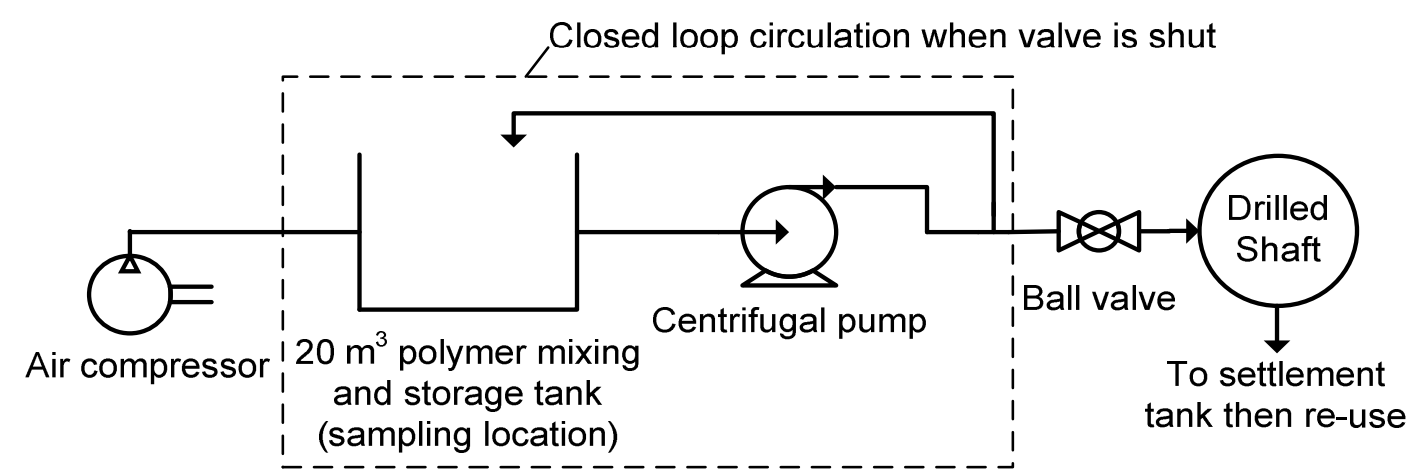

\section{FIG 1. Schematic of Plant Setup for Test Program}

Figure 1 shows a schematic diagram of the plant setup for this study. The PHPA fluids were mixed in a $20 \mathrm{~m}^{3}$ mixing and storage tank by sprinkling the required weight of dry PHPA granules into a stream of flowing water followed by gentle agitation with compressed air lances for about an hour. A centrifugal pump with a maximum capacity of $320 \mathrm{~m}^{3} / \mathrm{h}$ was connected between the tank and the drilled shaft. The pipe work was laid out so that the polymer fluid was recirculated back to the storage tank when the ball valve in the feed line to the excavation was shut. This meant that the pump did not need to be turned repeatedly off and on during excavation - an important aspect of plant operation as the pump and storage tank may be at some distance from the excavation.

During the test period, samples of the PHPA fluid were taken from the storage tank and tested with a Marsh funnel, which is a crude but a simple way of measuring the viscosity of support fluids in the field. The test basically involved filling the funnel with about 1.5 liter of the polymer fluid and measuring the efflux time for $946 \mathrm{~mL}$ (one U.S. quart) to flow out of the tip. The time in seconds was recorded as the Marsh funnel viscosity. Further details of the Marsh funnel test can be found in Darley and Gray (1988). Since the aim of the study was to assess the damage to the PHPA fluids caused by pumping, only clean fluids were used because samples taken from the drilled shafts could have been influenced by contaminants from the ground and would also contain suspended soil particles, which would affect the viscosity results.

\section{POLYMER MATERIALS AND MIXING DETAILS}

Two types of synthetic polymers were tested. Both were partially hydrolyzed polyacrylamides or PHPAs, which are copolymers of sodium acrylate $\left(\mathrm{CH}_{2}-\mathrm{CH}\right.$ $\mathrm{COONa})$ and acrylamide $\left(\mathrm{CH}_{2}-\mathrm{CH}-\mathrm{CONH}_{2}\right)$. The products used were in dry granular form although liquid emulsion forms of PHPA also are available. While both of the 
polymers tested were composed of the same two base components, it must be recognized that they may be considerably different in the ratio of these components, the length and geometry of their polymer chains, and most importantly in their performance characteristics. The suppliers of the PHPAs advised that their products were designed to work with a range of other chemical additives for enhanced shaft stability and soil-binding properties, but in this study only the base polymers were tested to reduce the number of variables.

Before addition of the PHPA granules, the $\mathrm{pH}$ of the make-up water was raised to between 10 and 11 . The polymer suppliers recommend this pre-treatment to minimize the negative effects of water hardness and other ionic species in the water so as to maximize the viscosifying potential of the polymers. The particular $\mathrm{pH}$ control agent used and the optimum $\mathrm{pH}$ value required varied between the two PHPAs. After treatment of the make-up water, the final $\mathrm{pH}$ was confirmed by 4-colour indicator papers and the desired amount of PHPA granules slowly poured into a stream of water flowing into a tank under the gentle agitation with compressed air.

The PHPA concentrations used were determined following the suppliers' guidelines for the expected site conditions. The actual dosages are given in Table 1 from which it can be seen that the concentration of PHPA in Fluid B per cubic meter of water was $30 \%$ less than that in Fluid A. Although to the user there may be no obvious reason for the significant difference in the suggested dosage, it must be recognized that polymers are chemical systems formulated by the suppliers and it is therefore appropriate to respect their recommendations. By doing so, the test fluids would also have similar properties to those used on other sites with similar ground conditions.

The PHPA fluids used in the trials did not require a long hydration period for viscosity development such as is required for bentonite slurries. However, to ensure that further dissolution of PHPA solids did not affect the test results they were prepared a day in advance of use. Table 1 summarizes the data on the PHPA materials and the make-up water.

Table 1. Summary of PHPA and Make-up Water Data

\begin{tabular}{|c|c|c|c|c|}
\hline $\begin{array}{c}\text { PHPA } \\
\text { polymer } \\
\text { designation }\end{array}$ & $\begin{array}{c}\text { PHPA } \\
\text { concentration } \\
\left(\mathrm{kg} / \mathrm{m}^{3}\right)\end{array}$ & $\begin{array}{c}\mathrm{pH} \text { adjustment } \\
\text { agent }\end{array}$ & $\begin{array}{c}\text { Water } \\
\text { hardness } \\
(\mathrm{mg} / \mathrm{L})\end{array}$ & $\begin{array}{c}\text { Original and } \\
\text { final } \mathrm{pH} \text { of } \\
\text { make-up water }\end{array}$ \\
\hline Fluid A & 0.90 & $\begin{array}{c}\text { alkali } \\
\text { hydroxide }\end{array}$ & $\begin{array}{c}7.5 \text { as } \\
\text { calcium } \\
\text { carbonate }\end{array}$ & $8 / 11$ \\
\cline { 1 - 1 } Fluid B & 0.60 & $\begin{array}{c}\text { alkali } \\
\text { carbonate }\end{array}$ & (soft water $)$ & $8 / 10$ \\
\hline
\end{tabular}

Note: ${ }^{a}$ data obtained from Scottish Water for the central Glasgow area in year 2009.

Since this study was carried out on a working construction site, during the monitoring period the PHPA fluid was drawn off from the storage tank to support the 
drilling of shafts (Figure 1). For each polymer approximately $9 \mathrm{~m}^{3}$ of fluid were used in excavations during the test period, thus at the end of each trial approximately $11 \mathrm{~m}^{3}$ of fluid remained in the storage tank. To ensure identical test conditions between the two PHPAs, after completion of the first trial the storage tank was emptied and cleaned before the second PHPA fluid was mixed. The used fluid after concreting of the drilled shafts was routed to a separate storage tank so as not to contaminate the test fluids.

\section{RESULTS AND DISCUSSIONS}

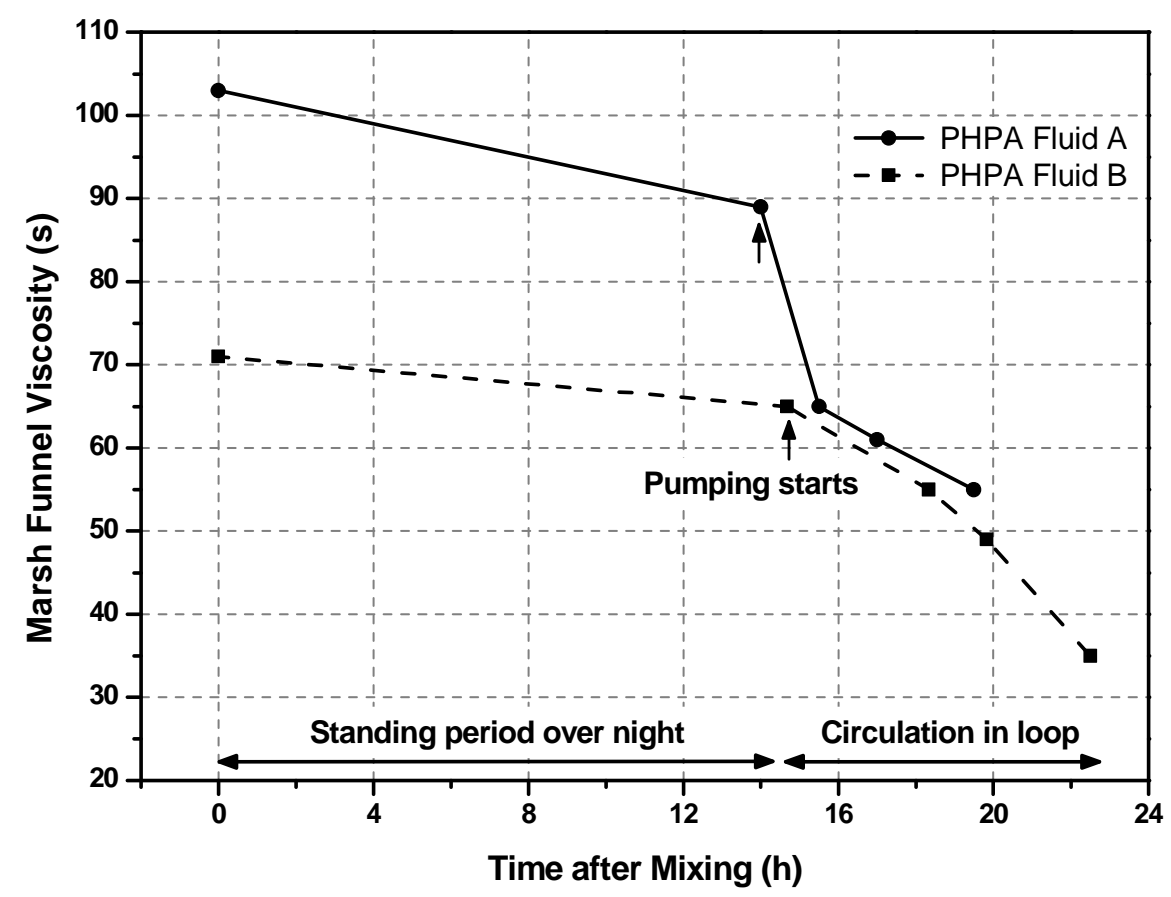

FIG. 2 Viscosity Change of PHPA Polymer Fluids

Figure 2 shows the results of the Marsh funnel viscosity tests for the two PHPA fluids for the whole test period. Interestingly, during the initial standing period between the end of mixing and the start of the pumping trial the following day, the viscosity dropped from 103 to $89 \mathrm{~s}$ for Fluid A and from 71 to $65 \mathrm{~s}$ for Fluid B, equivalent to a reduction of $14 \%$ and $9 \%$ respectively. This is a feature of PHPAs which is not always recognized, although the extra time will have allowed any undissolved PHPA granules to break up and also further disentanglement of polymer molecules to occur - both processes being expected to contribute to viscosity development. The storage tank was open at the top but as the weather during the test period was fine the fluids could not have been diluted by rainwater. Intermediate measurements during the overnight standing period were not practicable so it is not known how the viscosity reduction developed with time. This viscosity reduction has been the subject of further research, but this is beyond the scope of this paper. 
For each PHPA fluid, after the initial standing period of about 14 hours, the fluid began to be drawn off for shaft support. In the shafts, when the excavation reached the bottom of the surface casing fluid was pumped to the excavation. As digging progressed, the valve on the feed line was used by site staff to add further PHPA fluid to the excavation. The fluid level was always maintained at about $1.5 \mathrm{~m}$ below the ground level. When the fluid was not being drawn off for use, as previously discussed, the centrifugal pump continued to run and the PHPA fluid was recirculated to the storage tank (Figure 1).

As can be seen in Figure 2, the viscosity of both PHPA fluids dropped significantly as soon as pumping started. When excavation at the Fluid A supported drilled shaft was complete, the viscosity had dropped from 89 to $55 \mathrm{~s}$, which is equivalent to a reduction of $38 \%$ in viscosity. The situation with Fluid B was similar; it showed a drop from 65 to $35 \mathrm{~s}-$ a $46 \%$ reduction. Both PHPAs are understood to be of high molecular weight and it is believed that the reduction in viscosity was largely due to damage to the long-chain PHPA polymer molecules (molecular scission) caused by the strong mechanical action of the pump.

Towards the end of the monitoring period the rate of viscosity reduction appeared to accelerate. This is probably due to the fact that for each batch of PHPA a significant portion of the fluid had been drawn off to the excavation $\left(\sim 9 \mathrm{~m}^{3}\right)$ thus increasing the rate of recirculation of the fluid remaining in the storage tank. Finally, as we do not yet know the exact mechanism for the viscosity reduction during the standing period, it must be allowed that some of the reduction observed during the recirculation period may have been due to this mechanism. Therefore, the overall results may be the combination of effects of two totally different mechanisms.

It is also worth noting that, for both PHPA fluids, the reduction in viscosity seen during recirculation caused concerns about possible instability of the excavations. As a remedial measure, the viscosity was boosted by adding extra polymer materials directly into the holes. After completion of the monitoring work, all the remaining drilled shafts on the construction site were excavated under Fluid A with the additives recommended by the polymer supplier and were completed without any problems.

\section{CONCLUSIONS}

The viscosity of two PHPA polymer fluids has been monitored on a construction site in Glasgow, U.K. The results show that viscosity does not stay constant but tends to decrease over time even without any external interference; further research is needed to examine this behavior. The results presented here confirm the caution given in O'Neill and Reese (1999) that synthetic polymer fluids are susceptible to damage by centrifugal pumps, and in fact any pumping equipment which induces high shear stresses on the long-chain polymer molecules. Under the test conditions of this study, the viscosity of the two PHPA fluids dropped by $38 \%$ and $46 \%$ over a period of less than 10 hours. This reduction is clearly a function of the volume of the fluids in the system and the duration of the circulation. 
In the light of the findings from these brief trials, it is recommended that the use of centrifugal pumps be avoided and alternatives such as diaphragm pumps be sought. If diaphragm pumps are not available in the area of work, circulation of the PHPA fluids should be minimized. The pump should be switched off when not required to supply polymer fluid to the excavation. It is appreciated, however, that this suggestion may be difficult to implement unless the pump switches off automatically when the valve to the excavation is closed. It is also clear that regardless of the final selection of pumping equipment, the condition of the PHPA fluid should be checked regularly, so that any viscosity reduction can be identified and, if necessary, the fluid properties boosted. Furthermore, it seems prudent to prepare the fluids at a slightly higher viscosity than is actually required to allow for any potential reduction in viscosity on standing.

Although the trials showed that PHPA fluids are sensitive to the mechanical action of centrifugal pumps, this is actually an advantage in terms of energy use. Bentonite slurries require high shear, i.e. high energy mixing, and continued recirculation to develop their viscosity fully (Jefferis 1982). On the other hand, PHPA fluids can be mixed by simply pouring the granules into flowing water and do not require recirculation to develop their properties. The use of PHPA fluids and possibly other types of polymer products will therefore simplify site operations and reduce on-site energy consumption once appropriate plant is the norm.

Although both PHPA fluids tested in this study showed a similar degree of viscosity reduction, it is possible that some of the newer polymer products available in the market are less susceptible to damage by shear due to different chemistries and compositions. In fact, these products claim to rely less on their fluid viscosity and more on their soil-binding ability for shaft and trench support. Details of these polymer systems can be found in several U.S. patents by Goodhue et al. (2001, 2005). Research on these newer systems is in progress and will be reported in due course.

\section{ACKNOWLEDGMENTS}

The data presented in this paper was collected as part of a research project funded by the Engineering and Physical Sciences Research Council (EPSRC) in the U.K.; grant reference EP/C537815/1. The technical and financial support of Stent Foundations Ltd. is gratefully acknowledged as is the advice on polymer systems provided by KB International LLC and CETCO Construction Drilling Products. We would also like to thank Messrs. Viv Troughton, Allan Bowers, Chris Martin and Peter Martin for their continuing help and advice with the project.

\section{REFERENCES}

Brown, D., Muchard, M., and Khouri, B. (2002). "The effect of drilling fluid on axial capacity, Cape Fear River, NC." Proc., DFI $27^{\text {th }}$ Annual Conference on Deep Foundations, San Diego, CA, Deep Foundations Institute, Hawthorne, NJ. 
Bustamante, M. and Boato, R. (2005). "Polymer slurry in large diameter pile drilling - case histories." Proc., $16^{\text {th }}$ Int. Conference on Soil Mech. and Geotech. Engrg., Osaka, Japan: 2083-2086.

Corbet, S.P., Culley, D.S., Sherwood, D.E., and Cockcroft, J.E.M. (1991). "Testing and analysis of preliminary test piles in very weak chalk." Proc., $4^{\text {th }}$ Int. Conference on Piling and Deep Foundations, Stresa, Italy: 57-63.

Darley H.C.H. and Gray G.R. (1988). Composition and properties of drilling and completion fluids, $5^{\text {th }}$ Edition, Gulf Publishing Company, Houston, Texas, 643 p.

Fleming W.K. and Sliwinski Z.J. (1977). "The use and influence of bentonite in bored pile construction.", Report PG3, Construction Industry Research and Information Association, London, U.K., 93 p.

Goodhue, K.G., Jr., Holmes, M.M., Norman, C.S., and Wilkerson, J.M., III (2001). Composition and method for a dual-function soil-grouting excavating or boring fluid, U.S. Patent 6,248,697 B1, June 19, 2001.

Goodhue, K.G., Jr., Holmes, M.M., Norman, C.S., and Wilkerson, J.M., III (2005). Composition and method for dual function soil grouting excavating or boring fluid, U.S. Patent 6,897,186 B2, May 24, 2005.

Ho, C.E. and Tan, C.G. (1996). "Barrette foundation constructed under polymer slurry support in old alluvium." Proc., $12^{\text {th }}$ Southeast Asian Geotechnical Conference, Kuala Lumpur, Malaysia: 379-384.

Jefferis, S.A. (1982). "Effects of mixing on bentonite slurries and grouts." Proc., Specialty Conference in Grouting in Geotechnical Engineering, New Orleans, LA, ASCE: 62-77.

Majano, R.E., O’Neill, M.W., and Hassan, K.M. (1994). "Perimeter load transfer in model drilled shafts formed under slurry." J. Geotech. Engrg., 120(12): 2136-2154.

O’Neill, M.W. and Reese, L.C. (1999). "Drilled shafts: Construction procedures and design methods." Publ. No. FHWA-IF-99-025, Federal Highway Administration, U.S. Department of Transportation, Washington, D.C., 758 p. 